2017-10-01

Boldness is for rookies: prefight boldness and fighting success in a sea anemone

\title{
Lane, Sarah
}

http://hdl.handle.net/10026.1/9930

10.1016/j.anbehav.2017.07.012

Animal Behaviour

Elsevier BV

All content in PEARL is protected by copyright law. Author manuscripts are made available in accordance with publisher policies. Please cite only the published version using the details provided on the item record or document. In the absence of an open licence (e.g. Creative Commons), permissions for further reuse of content should be sought from the publisher or author. 


\section{A SEA ANEMONE}

3 Sarah M. Lane* \& Mark Briffa

4 Marine biology and ecology research centre, Plymouth University, Drake Circus, Plymouth,

5 UK, PL4 8AA

6 *Correspondence: Sarah M. Lane, Davy 620, Marine biology and ecology research centre,

7 Plymouth University, Drake Circus, Plymouth, UK, PL4 8AA

$8 \quad$ E-mail: sarah.lane@plymouth.ac.uk

Fighting experience (specifically winning or losing a fight) can significantly alter boldness, a component of resource holding potential (RHP). Previous studies have shown that both the repeatability of boldness and mean-level boldness can be affected by fighting experience and that these effects are strongest in the recipients of agonistic behaviour. However, whether these post-fight changes in boldness impact future contest success and whether subsequent contests further affect boldness remains unknown. Furthermore, little is known about the effects of the specific tactics used within a fight (within-fight experience) and how these might influence future fight performance and boldness. Here, we investigate the relationship between fighting success and boldness (measured as recovery time when startled) across repeated contests in the beadlet sea anemone Actinia equina, measuring boldness at 5 occasions before, between and after two contests. We found that boldness (both repeatability and mean-level) was generally robust to the 
effects of fighting experience, with the exception of a decrease in the immediate boldness of losers after their second fight. Furthermore, we found that while pre-fight boldness significantly predicted fighting success and the level of aggression used in an individual's first fight, it did not predict victory or aggression in the second fight. Our findings thus indicate that different traits may be important in determining fighting success in consecutive fights and moreover that fighting experience may alter which traits contribute to an individual's RHP.

Keywords: Actinia equina; boldness; fighting success; injuries; prior fighting experience; resource holding potential

INTRODUCTION

Resource holding potential (RHP) is comprised of a multitude of traits - including weapon size, body size, strength and endurance - all of which combine to determine an individual's ability to win a fight (Parker, 1974). Recently, RHP has been shown to be influenced not only by morphological and physiological traits but also by consistent between-individual differences in behaviour (personality traits), namely boldness (Barlow, Rogers, \& Fraley, 1986; reviewed in Briffa, Sneddon, \& Wilson, 2015). Boldness can be measured in different ways depending upon the species and context of interest. The most common measures include; exploratory behaviour in a novel environment (high/low), investigation of novel objects (readily/slowly) and recovery time when startled (fast/slow) (Briffa, Rundle, \& Fryer, 2008). As a component of RHP, boldness significantly affects the fighting success of individuals, for instance in the beadlet sea anemone Actinia equina - in which boldness has 
been measured as recovery time when startled (referred to hereafter as startle response) -

bolder individuals have been shown to inflict a higher number of attacks and win more fights than their shyer counterparts (Rudin \& Briffa, 2012). However bolder is not always better. In the asymmetric contests of the hermit crab Pagurus bernhardus, an attacker's chance of winning is not influenced by its boldness (startle response duration) but shyer individuals are better able to defend their shells from eviction (Courtene-Jones \& Briffa, 2014).

The experience of winning or losing a fight can significantly alter traits contributing to RHP which can in turn affect behaviour and success in subsequent contests (Hsu \&Wolf, 2001; Rutte, Taborsky, \& Brinkhof, 2006). The effect of fighting experience on boldness has thus far been investigated in only a handful of studies (willingness to approach a novel object - Frost, Winrow-Giffen, Ashley, \& Sneddon, 2007; startle response duration- Rudin \& Briffa, 2012; Courtene-Jones \& Briffa, 2014), the results of which demonstrate that fighting experience (specifically, winning or losing a fight) significantly affects both the repeatability of boldness and mean-level boldness, with the most extreme effects being seen in the recipients of agonistic behaviour, i.e. losers and defenders (Courtene-Jones \& Briffa, 2014; Rudin \& Briffa, 2012). For example, in P. bernhardus, defenders showed a significant reduction in the repeatability of boldness (measured as startle response) after fighting, while the boldness of attackers remained stable across situations (Courtene-Jones \& Briffa, 2014). Furthermore the mean-level post-fight boldness of defenders varied with the intensity of agonistic behaviours they were subjected to during the fight. In A. equina, prefight boldness was highly repeatable for both eventual winners and losers but the post-fight boldness of losers was not repeatable at all. Losers also showed a significant reduction in 
mean-level boldness (Rudin \& Briffa, 2012). Although these studies provide evidence that

fighting experience (specifically winning or losing a fight) can significantly affect the consistency and level of boldness, measures of pre-fight boldness were only compared with one or two post-fight measures, and as such it is unclear how long the observed post-fight changes in boldness persist. Moreover, if boldness contributes to RHP, then post-fight changes in boldness could alter the potential to win subsequent fights.

However, it is not just the outcome of a fight that can affect an individual's future contest behaviour/success, but also what happens during a fight (referred to hereafter as within-fight experience). Within-fight experience can vary in terms of outcome (winning or losing - as discussed above), level of aggression/escalation, tactics employed, duration and injury (both receiving and inflicting injuries; Lane \& Briffa, 2017). Injuries can significantly affect subsequent contest performance by reducing fighting ability. For example, in blue crabs Callinectes sapidus Rathbun (Smith, 1992) and stomatopods Gonodactylus bredini (Berzins \& Caldwell, 1983), injury affects an individual's ability to retain possession of females and territories respectively, with injured individuals losing to intact opponents. Injury has also been shown to interact with correlates of RHP to determine fighting success. For instance in the jumping spider Trite planiceps, body size is a major predictor of fight outcome in intact individuals, with larger individuals being more likely to win as the size difference between opponents increases. However, this size advantage diminishes when an individual is injured (Taylor \& Jackson, 2003), the most injured rival being more likely to lose regardless of size difference. While these studies all indicate that injury can have a significant effect on subsequent fighting success, all three were carried out on individuals who had been injured in ways other than through fighting itself (autotomy of unknown 
cause - Smith, 1992; Taylor \& Jackson, 2003; surgically injured - Berzins \& Caldwell, 1983), and thus the direct effect of injuries sustained in fights on future contest performance remains unclear.

Although previous studies have compared the effects of winning and losing fights against individuals that have not fought, little is known about the effects of the specific tactics used within a fight and how these might influence future fight performance and boldness. Understanding whether there is a link between aggressive performance and repeatable behaviour is important because it has been suggested that both fighting behaviour and consistent behavioural differences between individuals can be explained by negative frequency dependent selection (e.g. Wolf \& Weissing, 2010). Here, we investigate the relationship between boldness and within-fight experience in the beadlet sea anemone Actinia equina, where the outcomes of the fight can be win, lose or draw (i.e. no clear winner). Although lacking a centralised nervous system, $A$. equina possess weapons in the form of specialised stinging structures called acrorhagi which contain high concentrations of stinging cells (nematocytes) and are used during fights with conspecifics (Williams, 1978; Brace, Pavey, \& Quickie, 1979; Bigger, 1982). As mentioned above, boldness is a known component of RHP in A. equina and has previously been shown to be affected by winning or losing a fight (Rudin \& Briffa, 2012). Thus far however, post-fight boldness has been measured only once and thus the extent to which fighting experience affects boldness in the longer term, the extent to which it affects the repeatability of boldness, and hence the

111 effect that these changes could have on future fights, is unclear. Although not all contests in 112 A. equina result in injuries, when fights do escalate, anemones drag inflated acrorhagi along 113 the body column of their opponent, leaving behind nematocyte-filled ectoderm which rips 
114 off from their acrorhagi (referred to hereafter as 'peels'). These assaults injure the attacker

115 as well as the recipient and thus are potentially costly to both contestants (Lane \& Briffa,

116 2017). In this study we aimed to examine (i) how boldness contributes to fighting success

117 across multiple contests, (ii) how post-fight changes in boldness affect subsequent contest

118 success (iii) if and how subsequent contests further affect boldness and (iv) how injury state

119 and contest outcome (of focal and opponent) influence the effect of boldness on

120 subsequent fighting success. We therefore measured boldness before, between and after

121 two staged contests using startle response duration as our index of boldness (startle

122 response duration has previously been shown to provide highly repeatable measures of

123 boldness in A. equina, Bigger 1982; Briffa \& Greenaway, 2011; Rudin \& Briffa, 2012).

MATERIALS AND METHODS

Anemone collection and startle-response measures

127 Actinia equina ( $N=126)$ were collected from Portwrinkle (Cornwall, UK; grid reference: SX 357539) on 4 collection trips carried out between December 2015 and June 2016 (an average of 38 anemones collected on each trip) and taken back to the lab within 1-2 hours of collection. As in previous studies investigating aggression in A. equina, only anemones of the red/brown colour morph were collected. The red/brown morph has previously been shown to exhibit higher levels of aggression than anemones of the green/orange morphs

133 found lower down on the shore (Manuel, 1988). Once in the lab, anemones were 134 individually housed in plastic tanks $(23 \times 16 \times 17.5 \mathrm{~cm})$ containing $700 \mathrm{ml}$ of filtered, aerated 135 seawater and maintained in a controlled temperature room at $15^{\circ} \mathrm{C} \pm 0.5^{\circ} \mathrm{c}$. Throughout the 
experiment, anemones were fed ad libitum aquaria marine fish flakes every 2-3 days and seawater was changed every 7 days. from the shore, allowing the anemones time to habituate to the laboratory environment and attach their pedal discs to the side of their tank. The test was carried out by discharging a $5 \mathrm{ml}$ syringe full of seawater directly into the oral disc at a range of approximately $2 \mathrm{~cm}$ (Briffa \& Greenaway, 2011), causing the anemone to retract its tentacles. The anemone's response was calculated from the time the stimulus was applied until the point at which the anemone had re-opened fully to match its pre-stimulus state. Photographs were taken immediately before the stimulus was applied in order to accurately identify this state. The response was timed using a stopwatch and converted into seconds prior to analysis. Anemones were observed for a maximum of one hour after the stimulus was applied. If an anemone failed to reopen within the hour, no startle response time was recorded. This process was repeated early morning and late afternoon (with at least 6 hours between the morning and afternoon tests) for 2 days before the first fight and one last time the morning of the fight. It was then further repeated 5 times after the first fight to obtain 'betweenfight' measures of startle response and again 5 times after both fights in order to obtain 'after-fight' measures (15 measures per individual - see figure 1 for details). Between-fight measures of startle response were treated as post-fight startle responses with respect to fight 1 and pre-fight startle responses with respect to fight 2 (figure 1). The total number of startle response observations for each situation was as follows: Pre-fight $=231$ (82 anemones); Between-fights = 234 (78 anemones); After-fights=220 (78 anemones). 
160 On the morning of day 2 , the anemones were dislodged from their position on the tank 161 surface and their tanks lined with stones for them to attach to. The sides of the tank were 162 also lined with a thin layer of removable plastic in case the anemones re-adhered to the 163 tank walls. On the afternoon of day 3, anemones were randomly paired and placed into the 164 centre of a clean tank containing $700 \mathrm{ml}$ of aerated and filtered seawater. The anemones were positioned such that they were in contact with one another, which stimulates them to fight over territory. This was defined as the beginning of the fight and fights were considered concluded when one individual (the loser) either moved away from its opponent by an approximate distance of one pedal disc (estimated visually) or retracted its tentacles completely for at least 10 mins (Rudin \& Briffa, 2011; 2012). If both opponents performed these retreating behaviours, the outcome of the fight was classified as a draw. Contest duration was then back-calculated from the time of initial contact to the time at which the loser first began to move away from its opponent or first retracted its tentacles completely.

173 At the end of the contest, the number of acrorhagial peels inflicted on each opponent was counted and the fights were classified into two escalation categories -'no peel' or 'peel' depending on whether or not peels were inflicted. Anemones that failed to fight were removed from the experiment.

In order to observe the effects of within-fight experience and post-fight changes in boldness on future contest success and behaviour, a second fight was staged on the afternoon of day 10. In order to investigate how the prior contest outcomes of the focal and opponent interact to affect subsequent fights, individuals from the first fights were paired according to their victory status (winner or loser - individuals who drew in their first fight 
182

183

184

185

were excluded from the rest of the study $[N=6]$ ) in a fully orthogonal design. Individuals were randomly allocated as either focal (F) or opponent $(\mathrm{O})$ for the second fight based on their first fight ID, i.e. the pair of anemones that fought in first fight 1 were allocated as focal individuals in the second fight while the anemone pair that fought in first fight 2 were allocated as opponents in the second fight and so on. This resulted in a combination of four pairings of focal and opponent individuals: - winner $(F)-\operatorname{loser}(O)(N=10$ pairs); loser $(F)$ winner (O) ( $N=9$ pairs); winner (F) - winner (O) $(N=11$ pairs); loser $(F)-\operatorname{loser}(O)(N=11$ pairs) (A total of 41 focals and 41 opponents). Individuals were never re-paired with the same opponent from their previous fight. Fights were then staged as outlined above, but this time data were only taken for focal individuals within pairs. As before, anemones that failed to fight were removed from the experiment.

After both contests had taken place, the minimum and maximum pedal disc diameter of each anemone was measured using callipers to the nearest $0.1 \mathrm{~mm}$. As pedal disc shape is often elliptical, body size was then calculated as the average of the maximum and minimum diameter (Brace \& Quicke, 1986). A small piece of pedal disc tissue (approximately $1 \mathrm{~cm} \times 1 \mathrm{~cm}$ ) was removed using a scalpel and stored in $100 \%$ molecular grade ethanol for genetic analysis at a later date.

\section{Ethical Note}

After use in this study all anemones were returned to the collection site at Portwrinkle. No licences or permits were required for this study.

\section{Statistical analyses}


205 To determine the repeatability of startle response duration across fight outcomes (winner, 206 loser, draw), fight types (peel, no peel) and situations (pre-fight, post-fight), we conducted 207 Bayesian Markov chain Monte Carlo (MCMC) generalised linear-mixed models (using R package MCMCgImm, Hadfield, 2010) to calculate repeatability $(R)$ and its confidence

209 intervals separately for each round of fights (first, second) (Royauté, Buddle, \& Vincent, 210 2015). To determine the effect of fight outcome and situation (pre- or post- fight) on $R$, we

211 first created an outcome $x$ situation interaction variable containing all possible combinations

212 of outcome and situation. We then fitted a linear mixed model ( $\mathrm{Imm}$ ) with outcome,

213 situation and the outcome $\mathrm{x}$ situation interaction variable as fixed effects and the 214 interaction variable and ID as random effects. To determine the combined effect of fight

215 outcome, fight type and situation on $R$, we created an outcome $\mathrm{x}$ situation $\mathrm{x}$ fight type

216 interaction variable containing all possible combinations of outcome, situation and fight

217 type. We then fitted an Imm with outcome, situation, fight type and the interaction variable 218 as fixed effects alongside the interaction variable and ID as random effects. For both models, 219 we then extracted the situation and outcome (along with fight type for model 2) specific 220 posterior mode variance components (between individuals / G-structure, within individuals 221 / R-structure) and from these calculated posterior mode values for $R$. We then compared $R$ 222 values by calculating differences in repeatability $(\Delta R)$ across outcomes, fight types and situations. Differences were deemed to be significant if the $95 \% \mathrm{Cls}$ of $\Delta R$ did not span zero.

224 See appendix for more details on this approach. 
To investigate the relationships between boldness and within-fight experience we conducted a series of generalised linear-mixed models (glmms) using the R package Ime4

228 (Bates, Maechler, Bolker, \& Walker, 2015). Minimal adequate models were reached based on significance values gained from model comparison using likelihood ratio tests. variables, the type of model and error family changed depending on the nature of the response variable. For models with binary variables (fight outcome and fight type) as the response variable, a binomial error family was used in a glmm. Fixed effects included in these models were average pre-fight boldness, number of peels received and number of peels inflicted. Homoscedasticity was checked for by visual inspection of the model residuals. When examining the effect of first fight outcome on second fight outcome, first fight outcome was also included as a fixed effect. First fight ID was included in all models as a random effect to control for pseudoreplication resulting from taking two data points from the same fight. This was not necessary for the second fight as data points were only taken

240 from one (focal) individual per fight in this second contest. Individual ID was also included as 241 a random effect in models with startle response duration as the response variable since

242 there were multiple startle response durations for each individual. For models with continuous response variables (startle response duration, number of peels inflicted, number

244 of peels received), a linear mixed model ( $\mathrm{Imm}$ ) was used. Due to the non-normal distribution of startle response duration, this variable was log10 transformed before analysis. When analysing the effect of fight outcome on post-fight startle response duration, fight outcome, fight type and situation were included as fixed effects in the model. When analysing the effect of boldness and fighting experience on the number of peels inflicted and received in 
the second fight, average pre-fight boldness was included as a fixed effect. Relative size (RSD = 1-(opponent size/focal size)) and was included as a covariate in all models.

RESULTS

Pre-fight boldness as a predictor of fight outcome

In the first fight, average pre-fight boldness had a significant effect on fighting success $\left(X^{2}=\right.$ 4.37, $P=0.037$ ), with bolder individuals winning more fights than shyer individuals (figure 2a). Average pre-fight boldness also predicted whether or not an individual received $\left(X^{2}=\right.$ 4.28, $P=0.039)$ or inflicted peels $\left(X^{2}=8.59, P=0.003\right)$ in the first fight, with bolder individuals being more likely on average to inflict and receive peels than their shyer counterparts. In the second fight however, average pre-fight boldness (i.e. the startle responses recorded between the first and second fight) did not significantly predict the chance of victory $\left(X^{2}=1.01, P=0.31\right)$ or the likelihood of receiving $\left(X^{2}=0.53, P=0.47\right)$ or inflicting peels $\left(X^{2}=0.37, P=0.54\right)$, but rather predicted whether a fight ended in a clear outcome or in a draw $\left(X^{2}=3.91, P=0.048\right)$ (figure $\left.2 b\right)$, such that focal anemones that drew their second fight had longer startle responses prior to this fight than focal anemones that won or lost it. In order to check whether the loss of correlation between pre-fight boldness and the likelihood of inflicting peels was driving the breakdown of the link between pre-fight boldness and fighting success, we analysed second fights separately according to fight type. For both types of second fight (those that involved peels and those that did not) we again found that pre-fight boldness significantly affected whether a fight ended in a draw or a 
271 clear outcome (No Peels: $X^{2}=4.51, P=0.03$; Peels: $X^{2}=3.63, P=0.005$ ) but not whether an

272 individual won or lost (No Peels: $X^{2}=0.37$; Peels: $X^{2}=2.93, P=0.087$ ). There was no

273 significant effect of pre-fight boldness on the number of peels received ( $1^{\text {st }}$ fight: $X^{2}=1.25$,

274 $P=0.26 ; 2^{\text {nd }}$ fight: $\left.X^{2}=1.69, P=0.19\right)$ or inflicted $\left(1^{\text {st }}\right.$ fight: $X^{2}=0.05, P=0.82 ; 2^{\text {nd }}$ fight: $X^{2}=$

$2752 \mathrm{e}-04, P=0.99)$ in either fight. Relative size difference had no effect on either first $\left(X^{2}=1.48\right.$,

$276 P=0.22)$ or second fight outcome $\left(X^{2}=0.19, P=0.67\right)$.

277

278

Effect of fighting experience on boldness - repeatability and mean-level

Boldness (measured as startle response duration) was found to be significantly repeatable across all individuals, situations (pre-fight, between-fight and post-fight) and fights ( $1^{\text {st }}$ and

$2^{\text {nd }}$ fight) regardless of fight outcome (table 1). Furthermore, there was no significant effect of fight type on the repeatability of boldness in any of the three situations irrespective of victory status. The only exception was a significant difference in the repeatability of postfight boldness after the second fight between winners of 'no peel' fights and winners of fights involving peels. The post-fight boldness of individuals who won 'no peel' fights was significantly more repeatable than that of winners of fights involving peels (table 1).

First fight outcome had no effect on average $\left(X^{2}=1.15, P=0.28\right)$ or immediate (i.e. the first startle response in the sequence) post-fight boldness $\left(X^{2}=1.72, P=0.19\right)$. Second fight outcome on the other hand had a significant effect on immediate post-fight boldness.

290 Anemones that lost their second fight significantly increased their startle response in the first 24 hours post-fight $\left(X^{2}=8.65, P=0.01\right.$ ) (Figure 3). However this significant increase did not persist past these first 24 hours, with no significant difference in losers' average post- 
293 fight startle response $\left(X^{2}=3.99, P=0.14\right)$. The number of peels received in a fight had no 294 effect on average post-fight boldness in either the first $\left(X^{2}=0.03, P=0.87\right)$ or the second 295 fight $\left(X^{2}=0.21, P=0.65\right)$.

There was no significant effect of first fight outcome on second fight outcome $\left(X^{2}=0.13, P=\right.$ 0.722). There was also no effect of opponent victory status (i.e. whether they had won or

300 lost the first fight) on the second fight outcome of focal individuals $\left(X^{2}=0.17, P=0.68\right)$, nor was there a significant interaction between focal and opponent status $\left(X^{2}=1.84, P=0.18\right)$.

302 The number of peels inflicted in the first fight had no effect on second fight outcome $\left(X^{2}=\right.$ $0.52, P=0.47)$ and although there was a trend between the number of peels received in the

304 first fight and second fight outcome, this trend was not statistically significant $\left(X^{2}=3.18, P=\right.$ 305 0.07).

Resource holding potential is defined as a phenotypic trait that will increase the likelihood of victory in a contest. In contrast to motivational state, which should vary from encounter

310 to encounter, RHP traits might be subject to post-fight change but they should be relatively

311 stable between episodes of fighting. Although resource value dependent changes in

312 motivation within a fight can drive changes in startle response duration (Elwood \& Briffa

313 2001), this index of boldness is consistent between fights in several species. Since

314 individuals that are bolder outside of a fight situation show a higher probability of winning 
compared to shyer individuals, boldness appears to be an RHP component in many species.

316 For example, consistent pre-fight boldness been shown to predict subsequent fighting

317 success in the beadlet sea anemone Actinia equina (Rudin \& Briffa, 2012). However, our

318 findings indicate that in A.equina, boldness may only determine fighting success in an

319 individual's first fight. We found that in the first fight, pre-fight boldness determined

320 whether an individual won or lost, while in the second fight, boldness no longer influenced

321 an individual's victory but rather whether the fight ended in a draw or a clear outcome. Thus,

322 although consistent boldness appears to act as an RHP trait (determining the chance of

323 victory in a subsequent fight) its influence appears to vary with recent experience.

In agreement with previous work (Rudin \& Briffa, 2012), we found that pre-fight

boldness significantly predicted whether an individual won or lost a fight, bolder individuals

winning more fights on average than shyer individuals. However, this effect was only

present in the first fight, not the second fight. In the second fight, pre-fight boldness did not

predict fighting success per se but rather whether a fight ended in a clear outcome or a

draw, with shyer individuals drawing more often than bolder individuals. Pre-fight boldness

also had differential effects on the injury state of individuals across the two fights. In the

first fight, as well as predicting fighting success, pre-fight boldness predicted whether or not an individual inflicted or received peels. Bolder individuals were not only more likely to inflict peels (boldness has previously been found to covary with aggressiveness Huntingford, 1976; Rudin \& Briffa, 2012) but were also more likely to receive peels than their shyer counterparts. In the second fight, however, this correlation between boldness and injurious fighting was absent. This suggests that while shyer individuals were more likely to lose their first fight, they were less likely to become injured in the process. Low boldness 
also appears to have advantages in other examples of fighting. In the hermit crab Pagurus bernhardus, for example, shyer individuals are better able to resist eviction from their shells when attacked (Courtene-Jones \& Briffa, 2014). In the case of hermit crabs the advantage of being shy (at least when playing a defender-role) is obvious since these individuals are more

342 likely to win. In the present example of anemones the advantages of shy behaviour are less clear, since it was the bold individuals rather than the shy ones that were more likely to win.

344 Perhaps then, these differences between fight-outcomes for bold and shy anemones represent alternative strategies; bold individuals are more likely to win territory but at the cost of injuries, whereas shy individuals avoid injuries but at the cost of losing a territory.

347 Such a scenario has clear parallels with the predictions of the classic Hawk-Dove game

348 (Maynard Smith and Price 1973, Maynard Smith and Parker 1976), which predicts a stable 349 mix (i.e. a mixed evolutionarily stable strategy, ESS) of injurious and non-injurious fighting strategies if the costs of injury are (on average) greater than the value of the contested resource. Such a mix can arise in two ways, either through a mixture of consistently hawkish and dove-like individuals, or through a population of individuals that fluctuate between both strategies with the proportion of time playing each governed by the ratio of costs to resource value. Indeed, the actual agonistic behaviour of the anemones in this study indicates a relatively stable mix of injurious and non-injurious fighting since the proportion of fights with peels did not differ between the first and second fights. On the other hand the

357 link between boldness and fighting tactics does not appear to be stable since the effect of pre-fight boldness on the likelihood of inflicting or receiving injury in the first fight was absent in the second fight. 
It is important to note here that while we refer to these fights as 'first' and 'second',

the anemones used were collected from the wild, and are likely to have experienced fights

prior to this experiment. However, none of the anemones possessed any sign of injury from recent fights when collected from the shore and all individuals were housed for 7-14 days

before being fought. Thus while these may well not be their true first and second fights, any experience effects leftover from prior contests in the wild would very likely have dissipated by the time this experiment was run. Furthermore, we found no effect of prior fighting experience (winning or losing, receiving or inflicting injuries) on second fight outcome or behaviour, an absence which could possibly be due to the length of time between the first and second fight in our study being too long. It has previously been shown that the effects of fighting experience can last for very specific amounts of time, for example when male broad-horned flour beetles Gnatocerus cornutus lose fights, they exhibit behavioural changes which last for exactly four days after the fight, returning to their pre-fight state on day 5 (Okada, Yamane,\& Miyatake, 2010). However, as information on the duration of fighting experience effects in anemones is currently lacking we cannot make any conclusions about timing effects in $A$. equina. Although boldness is regarded as a highly repeatable behaviour in many species, previous studies have shown that both the repeatability of boldness and mean-level boldness can be significantly affected by fighting experience, especially in recipients of agonistic behaviour (Frost, Winrow-Giffen, Ashley, \& Sneddon, 2007; Rudin \& Briffa, 2012; Courtene-Jones \& Briffa, 2014; Briffa, Sneddon, \& Wilson, 2015). However, the results of our study illustrate that in A. equina boldness is generally robust to the effects of fighting 
experience. We found that boldness was significantly repeatable regardless of when it was measured (pre-fight, between-fights, post-fight) and furthermore that the repeatability of boldness was generally unaffected by an individual's within-fight experience (i.e. whether it won or lost, engaged in fights with or without peels). The only instance in which the repeatability of boldness was apparently altered was seen in winners after the second fight. Individuals who won fights involving peels exhibited significantly lower boldness repeatability than individuals who had won fights not involving peels, however there was no significant change in boldness repeatability within these groups across the two situations (i.e. between pre- and post-fight measures). This result may signify costs associated with competing in an injurious fight, especially as both inflicting and receiving injuries may pose costs in A. equina (Lane \& Briffa, 2017). Mean-level boldness also appeared generally robust to the effects of fighting experience, the only exception being a significant decrease in the immediate boldness of losers after the second fight. As previous work has found losers to be more susceptible to the effects of fighting experience on boldness (Frost, Winrow-Giffen, Ashley, \& Sneddon, 2007; Rudin \& Briffa, 2012; Courtene-Jones \& Briffa, 2014), this result is perhaps not surprising. However, why the first fight did not elicit a similar response in losers is unclear. It is possible that there may be a cumulative effect of fighting experience on the boldness of losers, but we did not detect any such effect in our study. individual's resource holding potential, which can in turn affect behaviour and success in

404 subsequent contests (Hsu \& Wolf, 2001; Rutte, Taborsky, \& Brinkhof, 2006). For example, 405 losing a fight can cause a reduction in RHP via injury or the physiological costs of fighting, causing individuals who have lost a fight to be more likely to lose the next fight they enter, a 
407 phenomenon known as the loser effect (winner effects also exist). While previous studies

408 have shown that fighting experience can significantly impact boldness, we have found the

409 opposite, that in A. equina, fighting experience (at least initially) has very little impact on

410 boldness but does affect the importance of boldness as an RHP trait, specifically the link

411 between boldness and fighting tactics that was present in the first fight was absent in the

412 second fight. Thus our study indicates that fighting experience can not only change an

413 individual's RHP (as shown elsewhere) but may also impact which traits contribute to RHP as

414 well. One example of such phenomena has been seen in the New Zealand jumping spider

415 Trite planiceps, in which the size advantage gained from being substantially bigger than your

416 opponent is lost once an individual is injured, relative injury level becoming more important

417 in determining fight outcome than relative size (Taylor \& Jackson, 2003).

Here we have shown that despite being a highly repeatable trait, robust to the

419 effects of fighting experience, boldness does not consistently predict fighting success in $A$.

420

equina, determining first fight but not second fight success. Our findings suggest that

421 different traits may be important in determining fighting success in consecutive fights and

422 moreover that fighting experience may alter which traits contribute to an individual's RHP.

423

\section{Acknowledgments}

425 We thank Ann Torr for help with collecting anemones. This study was funded by a BBSRC

426 grant awarded to M.B. (grant no. BB/ M019772/1). 
430 Barlow, G., Rogers, W., \& Fraley, N. (1986) Do Midas cichlids win through prowess or daring?

431 It depends. Behavioural Ecology \& Sociobiology, 19, 1-8.

432

433

Bates, D., Maechler, M., Bolker, B., \& Walker, S. (2015) Fitting linear mixed-effects models

434

using Ime4. Journal of Statistical Software, 67, 1-48. (doi: 10.18637/jss.v067.i01)

435

436

Bigger, C. H. (1982) The cellular basis of the aggressive acrorhagial response of sea-

437 anemones. Journal of Morphology, 173, 259-278.

438

439

Brace, R. C., Pavey, J., \& Quicke, D. L. J. (1979) Intraspecific aggression in the colour morphs

440 of the anemone Actinia equina: the convention governing dominance ranking. Animal

441 Behaviour, 27, 553-561.

442

443 Brace, R. C., \& Quicke, L. J. (1986) Dynamics of colonization by the beadlet anemone, Actinia 444 equina. Journal of the Marine Biological Association of the United Kingdom, 66, 21-47.

Briffa, M, Elwood, R. W., \& Dick, J. T. A. (1998) Analysis of repeated signals during shell fights in the hermit crab Pagurus bernhardus. Proceedings of the Royal Society B, 265, 1467-1474. 
449 Briffa, M., Rundle, S. D., \& Fryer, A. (2008) Comparing the strength of behavioural plasticity

450 and consistency across situations: animal personalities in the hermit crab Pagurus

451 bernhardus. Proceedings of the Royal Society B, 275, 1305-1311. (doi:

$452 \quad 10.1098 / \mathrm{rspb} .2008 .0025)$

453

454 Briffa, M., \& Greenaway, J. (2011) High In situ repeatability of behaviour indicates animal

455 personality in the beadlet anemone Actinia equina (Cnidaria). PLoS One, 6, e21963. (doi:

456 10.1371/journal.pone.0021963)

457

458 Briffa, M., Sneddon, L. U., \& Wilson, A. J. (2015) Animal personality as a cause and

459 consequence of contest behaviour. Biology Letters, 11, 20141007. (doi:

$460 \quad 10.1098 / \mathrm{rsbl} .2014 .1007)$

461

462 Courtene-Jones, W., \& Briffa, M. (2014) Boldness and asymmetric contests : role- and

463 outcome-dependent effects of fighting in hermit crabs. Behavioural Ecology, 25, 1073-1082.

464 (doi: 10.1093/beheco/aru085)

465

466 Elwood, R.W. \& Briffa, M. (2001) Information gathering and communication during agonistic

467 encounters: A case study of hermit crabs. Advances in the Study of Behavior, 30, 53-97. 
469 Frost, A., Winrow-Giffen, A., Ashley, P. J., \& Sneddon, L. U. (2007) Plasticity in animal 470 personality traits: does prior experience alter the degree of boldness? Proceedings of the 471 Royal Society B, 274, 333-339. (doi: 10.1098/rspb.2006.3751)

472

473 Hadfield, J. D. (2010) MCMC Methods for Multi-Response Generalized Linear Mixed Models:

474 The MCMCgImm R Package. Journal of Statistical Software, 33, 1-22. (URL: -

475 http://www.jstatsoft.org/v33/i02/.)

476

477 Hsu, Y., \& Wolf, L. L. (2001) The winner and loser effect: what fighting behaviours are 478 influenced? Animal Behaviour, 61, 777-786. (doi: 10.1006/anbe.2000.1650)

479

480 Lane, S. M. \& Briffa, M. (2017) The price of attack: rethinking damage costs in animal 481 contests. Animal Behaviour, 126, 23-229.

482

483

Manuel, R. L. (1988) British Anthozoa. Academic Press, London, UK.

484

485

Maynard Smith, J., \& Parker, G. A. (1976) The logic of asymmetric contests. Animal

486

Behaviour, 24, 159-175.

487 
490 Okada, K., Yamane, T., \& Miyatake, T. (2010) Ejaculatory strategies associated with 491 experience of losing. Biology Letters, 6, 593-596.

492

493

Parker, G. A. (1974) Assessment strategy and the evolution of fighting behaviour. Journal of 494 Theoretical Biology, 47, 223-243. (doi: 10.1016/0022-5193(74)90111-8)

495

496

Royauté, R., Buddle, C. M., \& Vincent, C. (2015) Under the influence : sublethal exposure to 497 an insecticide affects personality expression in a jumping spider. Functional Ecology, 29, 498 962-970. (doi: 10.1111/1365-2435.12413)

499

500 Rudin, F. S., \& Briffa, M. (2011) The logical polyp: assessments and decisions during contests 501 in the beadlet anemone Actinia equina. Behavioural Ecology, 22, 1278-1285. (doi:

502 10.1093/beheco/arr125)

503

504 Rudin, F. S., \& Briffa, M. (2012) Is boldness a resource-holding potential trait? Fighting 505 prowess and changes in startle response in the sea anemone Actinia equina. Proceedings of 506 the Royal Society B, 279, 1904-1910. (doi: 10.1098/rspb.2011.2418) 
508 Rutte, C., Taborsky, M., Brinkhof, \& M. W. G. (2006) What sets the odds of winning and

509 losing? Trends in Ecology and Evolution, 21, 16-21. (doi: 10.1016/j.tree.2005.10.014)

510

511 Williams, R. B. (1978) Some recent observations on acrorhagi of sea anemones. Journal of 512 the Marine Biological Association UK, 80, 719-724.

513

514 Wolf, M., \& Weissing, F. J. (2010) An explanatory framework for adaptive personality

515 difference. Philosophical Transactions of the Royal Society: B, 365, 3965-3968. (doi:

$516 \quad 10.1098 /$ rstb.2010.0215)

517

518

519

520

521

522

523

524

525

526

527 
Model specifications for comparing repeatability of boldness between fight outcomes and

\section{situations}

531

We first split data into 'first fight' (first fight outcome; pre-fight boldness; between-fights

532 boldness) and 'second fight' (second fight outcome; between-fights boldness; after-fights boldness), analysing these two sets separately in the following way.

534 We began by creating an outcome $\mathrm{x}$ situation interaction variable (referred to hereafter as

535 outcome_sit), accounting for every possible combination of outcome and situation. We then used an inverse-wishart prior $(V=\operatorname{diag}(n), n u=n)$, where $n$ is the number of behavioural

537 variables being considered and nu is the degree of belief parameter (Hadfield 2010) to incorporate all combinations of fight outcome and situation, resulting in a $6 \times 6$ matrix. We specified a Markov Chain Monte Carlo (MCMC) glmm with 50,000 iterations, a 30,000 iteration burn-in and a thinning level of 10 . This yielded an MCMC sample size of 2,000 and autocorrelation of $<0.1$ in all instances. We used a poisson error family due to the count

542 nature of our response variable (startle response duration) and included outcome, situation 543 and outcome_sit as fixed effects along with outcome_sit and ID as random effects. We then

544 extracted the outcome and situation specific posterior variance components (between

545 individuals/ G-structure/R-structure) from this model and used these to calculate posterior

546 mode values for repeatability (R) for each outcome _sit combination. Finally, we compared

$547 \quad \mathrm{R}$ values by calculating differences in repeatability $(\Delta \mathrm{R})$ across outcomes and situations. 
549 Model specifications for comparing repeatability of boldness between fight outcomes,

550 fight types and situations

551 We again split our data into 'first fight' and 'second fight' and analysed these two sets

552 separately.

553 We created an outcome $x$ fight type $x$ situation interaction variable (referred to hereafter as

554 outcome_type_sit), accounting for every possible combination of outcome, fight type and

555 situation. We again used an inverse-wishart prior to create a 12x12 matrix incorporating all

556 combinations of outcome, fight type and situation. We then specified an MCMCgImm with

557500,000 iterations, a 300,000 iteration burn-in and a thinning level of 10 . This yielded an

558 MCMC sample size of 20,000 and autocorrelation of $<0.1$ in all instances. We again used a

559 poisson error family to account for the count nature of our response variable (startle

560 response duration) and this time included outcome, situation, fight type and

561 outcome_type_sit as fixed effects alongside outcome_type_sit and ID as random effects.

562 We then extracted the outcome and situation specific posterior variance components

563 (between individuals/ G-structure/R-structure) from this model and used these to calculate

564 posterior mode values for repeatability (R) for each outcome _sit combination. Finally, we

565 compared $R$ values by calculating differences in repeatability $(\Delta R)$ across outcomes and

566 situations.

567

568

569 
571 Table 1 Repeatability of startle response duration (boldness) $\pm 95 \%$ confidence intervals

572 Repeatability of startle response duration (boldness) $\pm 95 \%$ confidence intervals (Cls) for 573 each combination of fight outcome and situation and each combination of fight outcome, 574 situation and fight type along with differences in repeatability $(\Delta R)$ between outcomes, 575 situations and fight types. Significant values (if the $95 \%$ Cls crossed zero) are indicated in 576 bold. 


\begin{tabular}{|c|c|c|c|c|c|c|}
\hline & Pre-fight 1 & $\begin{array}{l}\text { Between-fights } \\
\text { (post fight 1) }\end{array}$ & $\begin{array}{l}\Delta \mathrm{R} \text { (Pre-fight - } \\
\text { between-fights) }\end{array}$ & $\begin{array}{c}\text { Pre-fight } 2 \\
\text { (between fights) }\end{array}$ & After fights & $\begin{array}{c}\Delta \mathrm{R} \text { (between-fights - } \\
\text { after-fights) }\end{array}$ \\
\hline Winners & $0.32[0.18,0.51]$ & $0.25[0.15,0.46]$ & $-0.02[-0.28,0.18]$ & $0.35[0.15,0.46]$ & $0.36[0.18,0.64]$ & $0.07[-0.020,0.43]$ \\
\hline Losers & $0.20[0.11,0.26]$ & $0.22[0.13,0.41]$ & $0.002[-0.15,0.25]$ & $0.22[0.13,0.41]$ & $0.26[0.14,0.59]$ & $-0.22[-0.48,0.16]$ \\
\hline Drawers & - & - & - & $0.42[0.19,0.68]$ & $0.24[0.11,0.49]$ & $-0.13[-0.44,0.18]$ \\
\hline$\Delta \mathrm{R}$ (Winners - Losers) & $-0.08[-0.32,0.11]$ & $-0.02[-0.23,0.19]$ & - & $-0.02[-0.23,0.19]$ & $0.09[-0.28,0.38]$ & - \\
\hline$\Delta \mathrm{R}$ (Winners -Drawers) & - & - & - & $0.19[-0.17,0.46]$ & $0.12[-0.19,0.43]$ & - \\
\hline$\Delta \mathrm{R}$ (Losers-Drawers) & - & - & - & $0.15[-0.16,0.47]$ & $-0.03[-0.35,0.28]$ & - \\
\hline No Peels: Winners & $0.28[0.15,0.51]$ & $0.21[0.11,0.43]$ & $-0.04[-0.29,0.21]$ & $0.27[0.11,0.69]$ & $0.78[0.40,0.96]$ & $0.35[-0.09,0.74]$ \\
\hline No Peels: Losers & $0.29[0.15,0.51]$ & $0.19[0.10,0.39]$ & $0.03[-0.16,0.33]$ & $0.26[0.10,0.66]$ & $0.31[0.10,0.71]$ & $0.050[-0.43,0.46]$ \\
\hline No Peels: Drawers & - & - & - & $0.49[0.22,0.75]$ & $0.29[0.13,0.57]$ & $-0.19[-0.50,0.20]$ \\
\hline$\Delta \mathrm{R}$ (No Peels: Winners - Losers) & $0.20[-0.16,0.34]$ & $0.20[-0.30,0.20]$ & - & $0.01[-0.41,0.46]$ & $0.35[-0.10,0.75]$ & - \\
\hline$\Delta R$ (No Peels: Winners - Drawers) & - & - & - & $-0.18[-0.51,0.30]$ & $0.45[-0.02,0.71]$ & - \\
\hline$\Delta R$ (No Peels: Losers - Drawers) & - & - & - & $-0.17[-0.61,0.34]$ & $0.05[-0.44,0.51]$ & - \\
\hline Peels: Winners & $0.42[0.22,0.69]$ & $0.57[0.25,0.74]$ & $0.10[-0.32,0.41]$ & $0.34[0.13,0.60]$ & $0.22[0.10,0.54]$ & $-0.05[-0.40,0.29]$ \\
\hline Peels: Losers & $0.34[0.14,0.59]$ & $0.26[0.14,0.54]$ & $0.004[-0.36,0.27]$ & $0.31[0.13,0.63]$ & $0.38[0.15,0.71]$ & $-0.08[-0.48,0.39]$ \\
\hline Peels: Drawers & - & - & - & $0.48[0.12,0.88]$ & $0.25[0.22,0.75]$ & $-0.17[-0.65,0.44]$ \\
\hline$\Delta \mathrm{R}$ (Peels: Winners -Losers) & $0.20[-0.22,0.44]$ & $0.20[-0.13,0.52]$ & - & $0.001[-0.36,0.36]$ & $-0.09[-0.49,0.26]$ & - \\
\hline$\Delta \mathrm{R}$ (Peels: Winners -Drawers) & - & - & - & $-0.13[-0.58,0.34]$ & $-0.03[-0.54,0.35]$ & - \\
\hline$\Delta \mathrm{R}$ (Peels: Losers - Drawers) & - & - & - & $-0.16[-0.51,0.29]$ & $0.04[-0.34,0.45]$ & - \\
\hline$\Delta \mathrm{R}$ (Peels: Winners - No Peels: Winners) & $0.19[-0.13,0.47]$ & $0.22[-0.06,0.52]$ & - & $-0.05[-0.38,0.42]$ & $0.47[0.006,0.74]$ & - \\
\hline$\Delta \mathrm{R}$ (Peels: Losers - No Peels: Losers) & $-0.11[-0.41,0.13]$ & $-0.009[-0.30,0.27]$ & - & $0.006[-0.40,0.40]$ & $0.078[-0.34,0.45]$ & - \\
\hline$\Delta \mathrm{R}$ (Peels: Drawers - No Peels: Drawers) & - & - & - & $0.04[-0.47,0.49]$ & $0.05[-0.49,0.38]$ & - \\
\hline
\end{tabular}

\section{8}



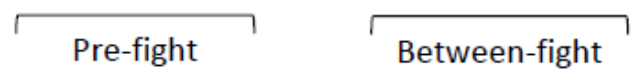

After-fight

582

583

584

$\begin{array}{lllllllll}\text { SR1 } & \text { SR3 } & & \text { SR6 } & \text { SR8 } & & \text { SR11 } & \text { SR13 } & \\ \text { SR2 } & \text { SR4 } & \text { SR5 } & \text { SR7 } & \text { SR9 } & \text { SR10 } & \text { SR12 } & \text { SR14 } & \text { SR15 }\end{array}$

585 Figure 1 Overview of the experimental structure. Between-fight startle responses (SR) were

586 treated as post-fight responses with respect to fight 1 and pre-fight responses with respect

587 to fight 2 .
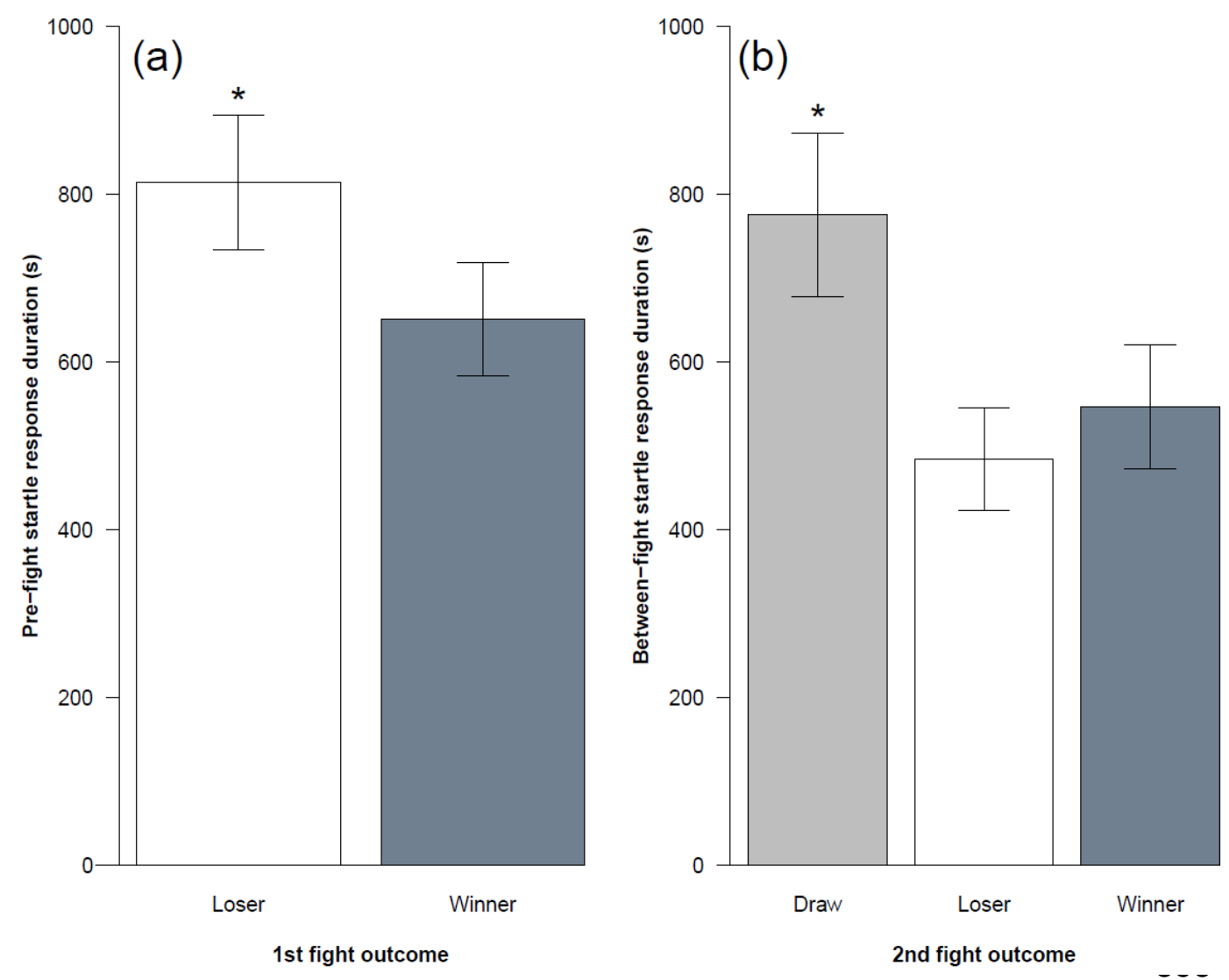

597 Figure 2 Effect of mean $( \pm S E)$ pre-fight startle response time on (a) first fight outcome and (b) second fight outcome. Asterisks indicate significant differences within each panel. 


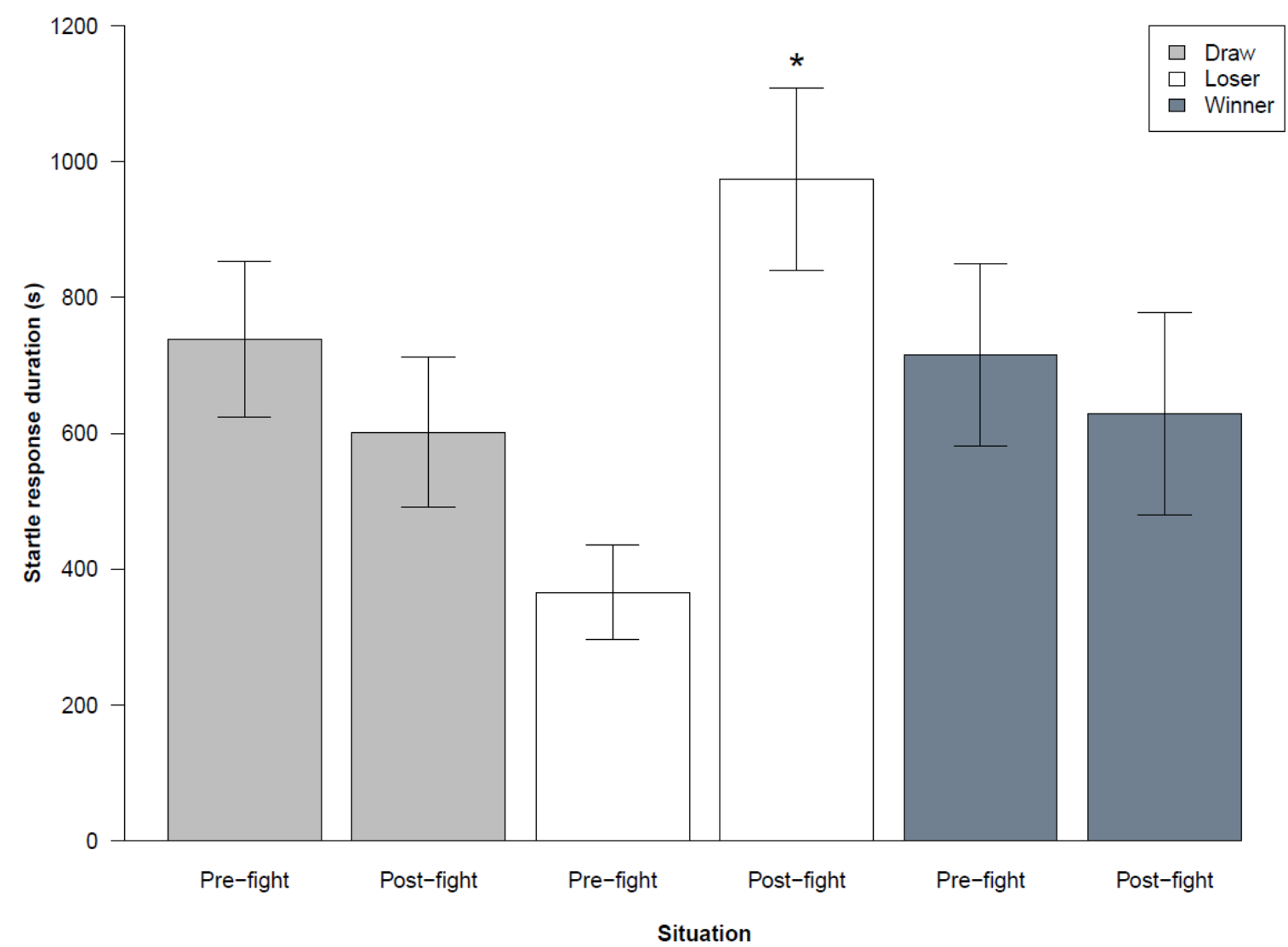

599 Figure 3 Mean $( \pm S E)$ startle response duration immediately before and immediately after

600 the second fight. 